Sławomir P. Bartnicki

\title{
SPATIAL IMAGES OF CRIME IN WARSAW
}

It has now been almost twenty years since geographers took interest in crime as the object of the spatial analysis, which caused the rise of a new sub-discipline in geography, that is the geography of crime. During those years, geography of crime, which was initially aimed at cartographic representation of spatial differentiation of the phenomenon, turned into a complex discipline that treats spatial inequality of distribution of crime indices as a basis for more complex studies on the relationship between space, society and crime.

Generally speaking, two basic research trends can be distinguished in the contemporary geography of crime. The first trend, dealing first of all with the mapping of objective and published in official records statistical figures on crime and its consequences. (for example, material losses) or investigation of ecological associations, if any, of crime (in the sense of human ecology), may be called an objective geography of crime. The other trend, which is aimed at the analysis of social perception of the phenomenon, focuses on the analysis of the images of crime, spatial systems of fear of crime or the outcomes of this fear which are seen, for example, in adaptation of spatial behaviours to the images of threat. The latter trend can be termed a subjective geography of crime.

At first, geographers' interest in criminological analyses was chiefly focused on studies which can be ascribed to the first trend. At present these two currents are almost equally important. Results of studies based in a way on objective data taken from the police records are more increasingly supplemented with the analyses of information received from various questionnaires and other fieldwork studies, which are the main information source for the subjective geography of crime.

Interesting results are also supplied by the investigation of the compatibility of spatial patterns of actual crime of which the image is obtained from the mapping of the police records, with the spatial systems of images of crime, images of threat or the feelings of safety. This issue is so important because, in case these objective and subjective spatial patterns of crime are compatible, the chief purpose of the research comes to be 
the analysis of human response in dangerous environment and their behavioural adaptations ( $\mathrm{cf}$. Brantingham and Brantingham 1982). When these patterns are different, the main aim of the researcher is to analyse causes of the rise of such incompatibility.

Among the latest geographical publications on subjective aspects of crime, one should mention an interesting and pioneer work entitled Perceptions of Crime and Sufety in Three Midwestern Parks (Westover 1985). In order to investigate the relationship between the particular elements of the process of the rise of fear of crime and the ensuing social response, the author of the analysis has made use of a general scheme of the process as suggested by Garofalo (1981) (cf. Fig. 1). The scheme suggests a certain sequence in the process of the rise of fear of crime: information about crime - image of crime - risk assessment rise of fear - response. Other studies show that additional important elernents that should be taken into consideration in the analysis of the fear of crime are the following: attitude towards crime - against a background of the attitude towards other important social issues - feelings of safety and ecological labeling (the rise and impact of certain stereotypes on images) (cf. Brantingham and Brantingham 1982).

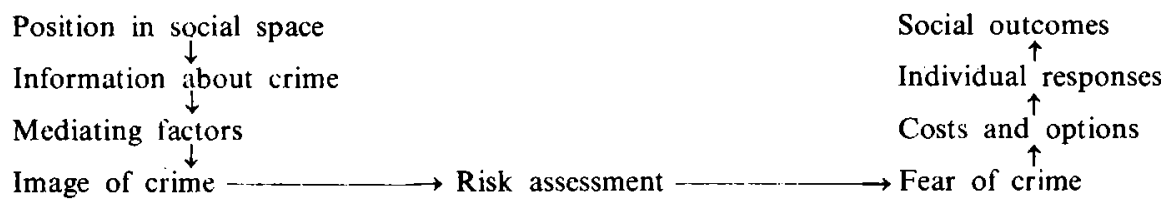

Fig. 1. General scheme of the rise of fear of crime according to Garofalo. 1981

The approach which emphasises the impact of stereotypes on human behaviour, suggests that people have permanent images of particularly dangerous places (Brantingham and Brantingham 1982). Some places in cities are generally regarded as more dangerous than others. Thus, one of the most important, and not taken into consideration by the Garofalo scheme, elements of the rise of the image of crime is the rise and persistence of certain stereotypes.

At the same time, it should be emphasised that the familiar surroundings, particularly those closer to one's place of residence, are usually regarded as safer than other places that are situated farther and unfamiliar.

Thus we may distinguish at least two - independent to a certain extent - components of the spatial image of crime. The first one is bound up with getting aware of one's attitude towards the given place on the grounds known vs unknown, and the other is related to the occurrence of certain stereotypes in social consciousness. The stereotypes, also called ecological labels, are to a certain extent an expression of expectation of certain behaviours in certain places. 
The emphasis laid on two "dimensions" of the image of crime is aimed at showing that although the investigation of the "feelings of safety" and "fear of crime" is usually tantamount to the analysis of the same phenomenon, "safety" and "fear" are measures of various kinds of perception of crime. Whereas the sense of threat, the level of fear of crime or the image of the particular "criminal vulnerability" of some districts of the town are highly influenced, as it seems, by the existent stereotypes (sustained or refuted, for example, by the mass media), the sense of safety or the image of an exceptional "criminal resistance" is to a larger extent a function of the familliarity of the given place, which means in some cases the function of distance.

Thus, one may risk a statement that the maps representing the image of safety of the particular places in the town will not be just negatives of maps representing the images of the particular criminality of some districts, since these images are being shaped by various factors: "space of threat" is shaped to a considerable extent by the existent stereotypes of the particularly dangerous places and the shaping of the "safety space" largely depends on the place of residence of a person whose image is being investigated.

In order to verify the above-mentioned hypothesis, the investigation was conducted of the threat/safety image of 230 students of secondory schools of seven Warsaw's administrative districts, namely Żoliborz, Wola, Śródmieście, Ochota and Mokotów, as well as Praga Poludnie and Praga Północ. The questionnaire was conducted in 1984 and each student was asked, among other things, to mention five (he was given the list of names of thirty-seven residential districts of Warsaw) districts he considered most vulnerable to burglary. Next, the student was asked to mention five safest districts.

From the obtained ranking of the residential districts, making use of the Gould and White (1974) method, calculations were made of the indices of the perceived threat/safety. The value of the index amounting to 100 on the enclosed maps informs us that a given territorial unit was perceived by the inhabitants of the given district as: (a) the safest (for maps representing the image of the feelings of safety) or (b) most vulnerable (for maps depicting the image of threat).

Although the whole questionnaire comprised the images of the inhabitants of seven districts, the present paper includes only the images of the inhabitants of Ochota and Praga Południe districts. Thus only four maps are attached to this paper. Figures 2 and 3 depict the image of burglary threat of the inhabitants of Ochota and Praga Południe districts. Figures 4 and 5 represent the image of the safest, as far as burglary is concerned, districts of Warsaw as seen from the perspective of Ochota and Praga Południe districts. 


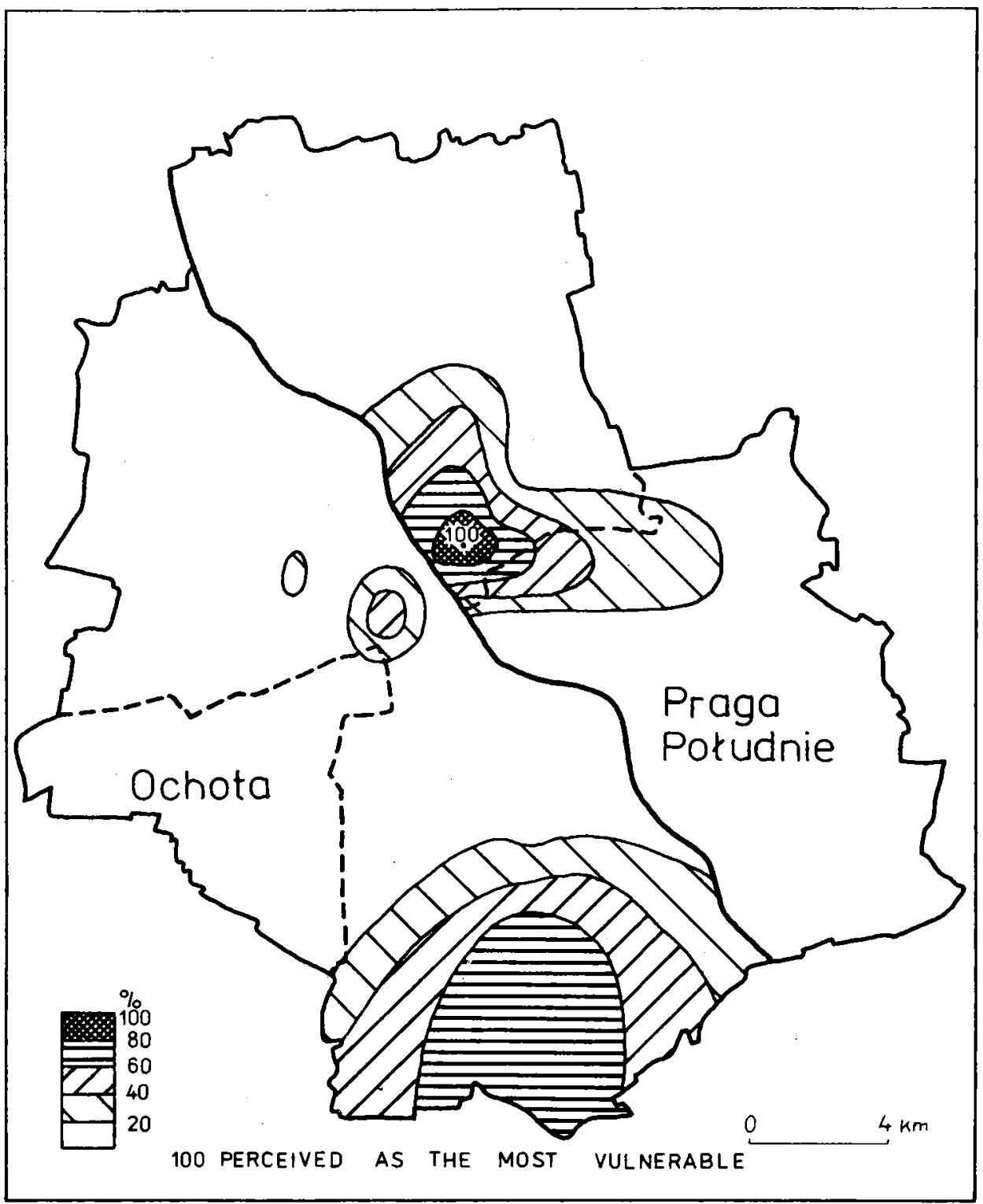

Fig. 2. Image of burglary threat in the districts of Warsaw as revealed by the inhabitants of Ochota district 


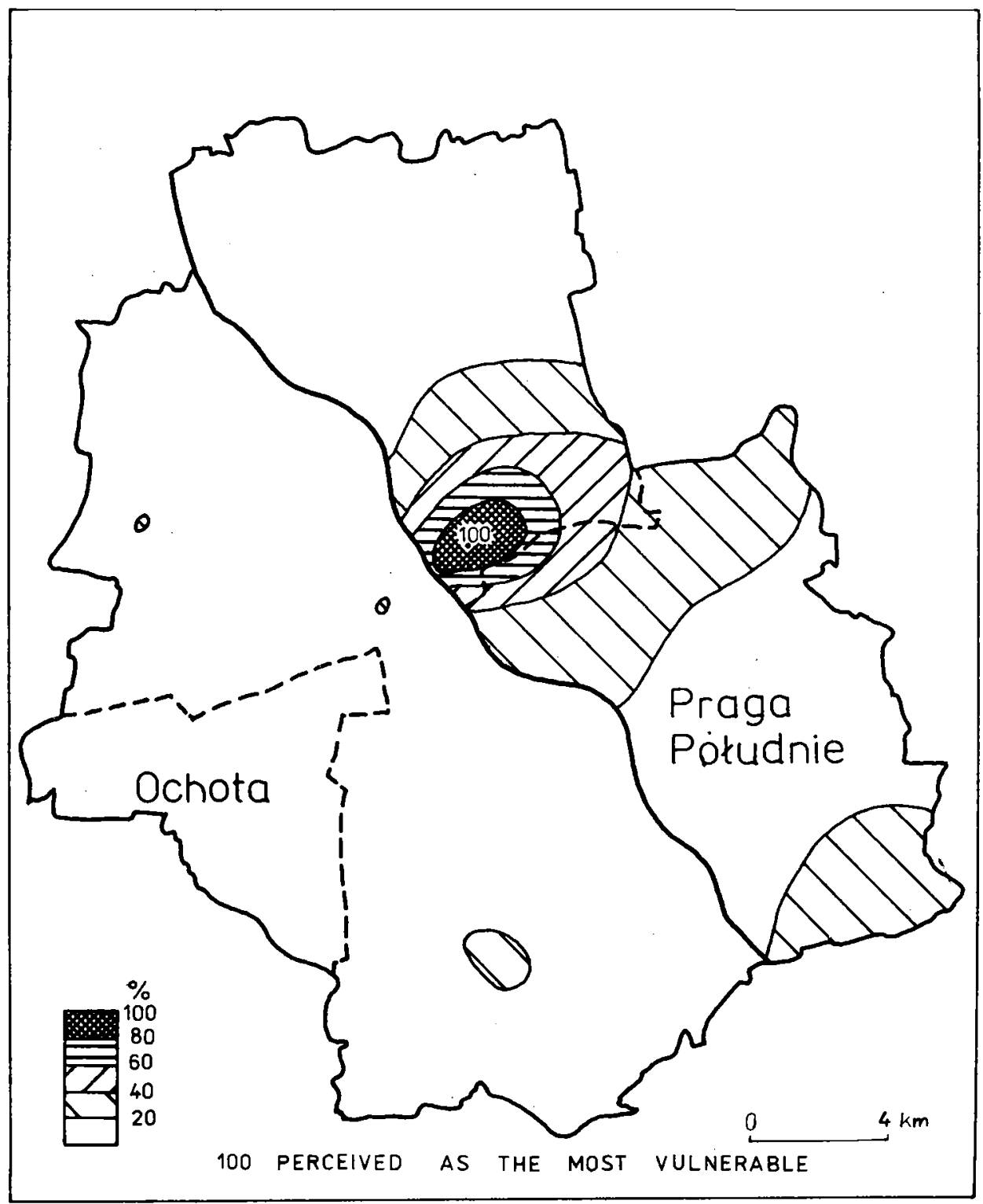

Fig. 3. Image of burglary threat in the districts of Warsaw as revealed by the inhabitants of Praga Potudnie 


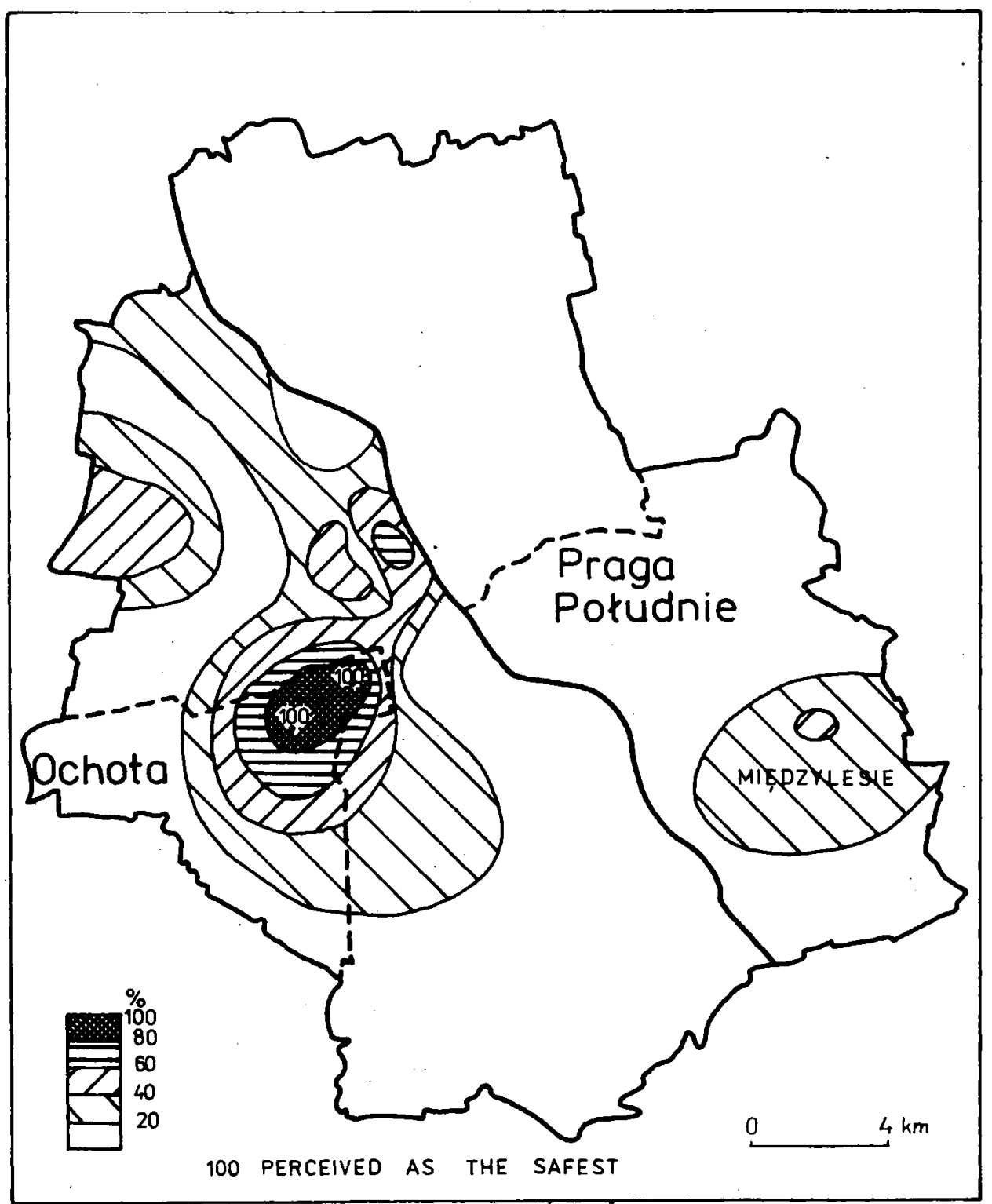

Fig. 4. Image of safety of the particular districts of Warsaw as revealed by the inhabitants of Ochota district 


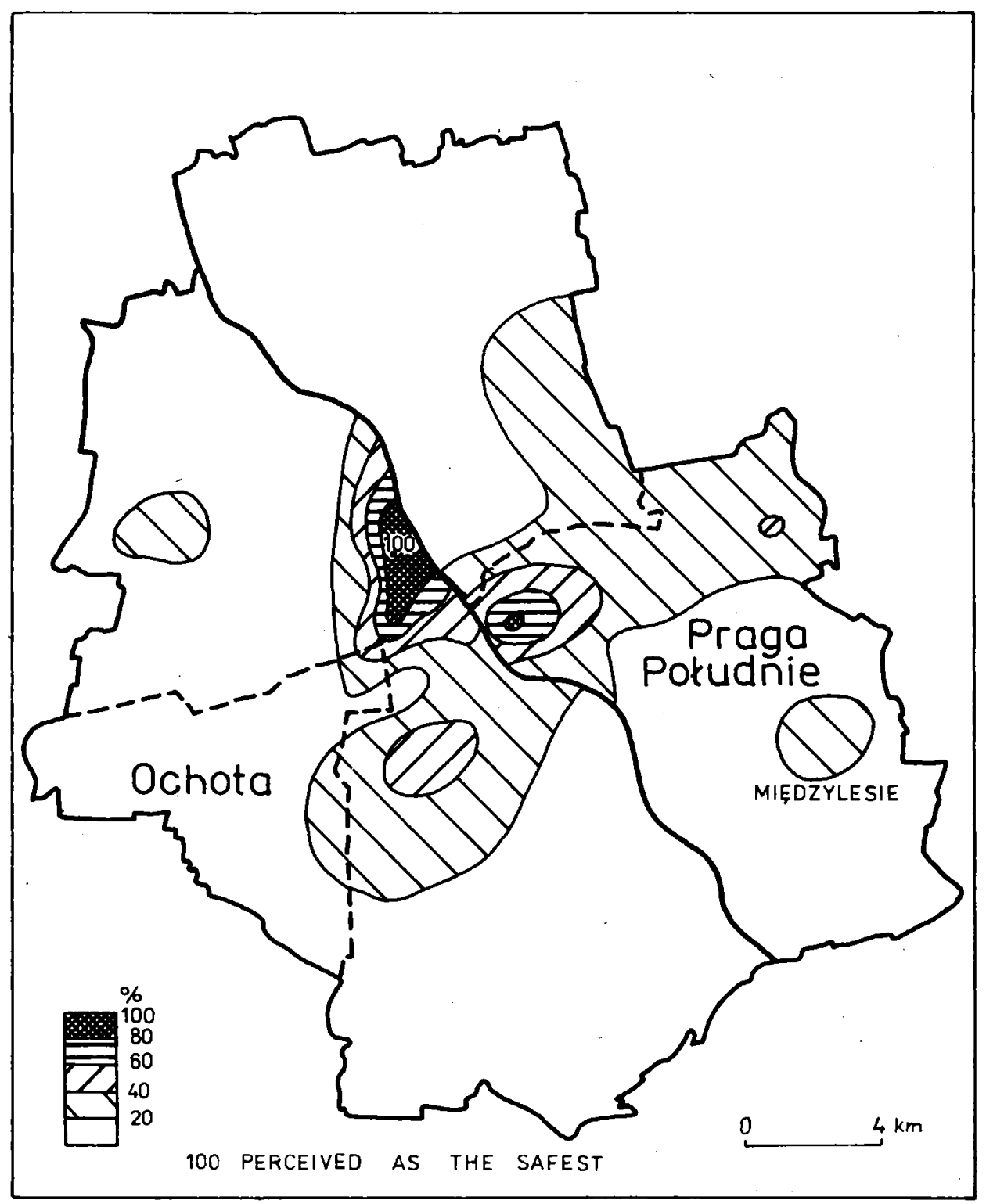

Fig. 5. Image of safety of the particular districts of Warsaw as revealed by the inhabitants of Praga Południe 


\section{CONCLUSIONS}

1. According to the scheme presented above, the image of burglary threat of the particular districts of Warsaw should be shaped in the first place by the stereotypes existing in the consciousness of the inhabitants of both left-bank (Ochota district) and right-bank (Praga Poludnie district) Warsaw. Therefore the map depicting the images of burglary threat drawn on the basis of the information obtained from the inhabitants of the Ochota district should resemble the map representing the images of burglary threat of the particular residential districts revealed by the inhabitants of the Praga Południe district. Actually, in figures 2 and 3 a similar pattern is to be distinguished: the most threatened area is considered to be that in right-bank Warsaw, that is Targówek and Praga Centralna (the index value amounts there to the maximum). Besides, both the inhabitants of Ochota and those of Praga Poludnie regard the new districts of Ursynów-Natolin (in the southern left-bank Warsaw) as the area which is particularly threatened. It is worthwhile emphasising that this image is compatible with the real picture emerging from the official statistics. Both the districts of Targówek and Praga Centralna, as well as those of Ursynów and Natolin, are among those most threatened with burglary (cf Bartnicki 1986).

2. Quite different are the maps which represent spatial images of those residential districts which are considered by the inhabitants of Ochota and Praga Poludnie as the safest ones. In this case the hypothesis is confirmed that it is the districts which are best known and situated near one's place of residence that are regarded as the safest ones. The inhabitants of Ochota were almost unanimous to stress that the safest districts of Warsaw are the left-bank districts of Ochota Centralna and Śródmieście (see Figure 4). The image resembles to a large extent the picture presented on the maps of the actual burglary threat which show that those districts do belong to the safest ones (cf Bartnicki 1986). Quite different is the cartographic picture of the "safety area" which results from the analysis of the images of the inhabitants of Praga Poludnie. They regard as the safest ones the right-bank district of Saska Kepa and, similarly as the inhabitants of Ochota, Śródmieście and Stare Miasto (the Old Town) (Fig. 5). It is interesting to note that in both cases the district of Miedzylesie is regarded as a safe district, while in reality it is quite highly threatened with burglary.

3. One of the measures of compatibility of the systems of spatial images revealed by the irthabitants of Ochota and Praga Poludnie is the rank correlation coefficient. It has been calculated both for the sake of comparison of similarity of the systems of images of threat and the compatibility of spatial distribution of image of safety of the particular districts of Warsaw. In the former case $r=0.6$, while in the latter case 
$r=0.17$. Thus it can be concluded that the hypothesis about the occurrence of two components bearing impact on spatial images of crime has been confirmed. A defintely higher compatibility of images of threat $(r=0.6)$ than of safety $(r=0.17)$ indicates that there exist extremely strong stereotypes of dangerous areas (Praga Centralna, Targówek, Bródno) that are shared by the inhabitants of Ochota and Praga Poludnie. At the same time, high impact of the place of residence on the image of safety finds its reflection in a small similarity of spatial images revealed by the inhabitants of those districts.

\section{REFERENCES}

B a rtnicki, S. P., 1986, "The Geography of Crime. A Case Study of Warsaw", in: Miscellanea Geographica, 1986, pp. 237-242.

B rant ingh a m, P. L., B r a $\mathrm{t}$ ingh a m, P. J., But cher, D., 1982, Perceived and Actual Crime Risks: An Analysis of Inconsistencies, 21 Annual Meeting, Western Regional Science Association, Santa Barbara, February 1982.

Gar of a lo, J., 1981, "The Fear of Crime. Causes and Consequences", The Journal of Criminal Law and Criminology, 72, pp. 839-857.

G o u 1 d, P., Wh it e, R., 1974, Mental Maps, Penguin Books, London.

We st over, T. N., 1985, "Perceptions of Crime and Safety in Three Midwestern Parks", Professional Geographer 37, pp. 410-420. 
